\title{
A Modern Authors Collection at the University of Tulsa
}

\author{
By THOMAS F. STALEY
}

IN MARCH of 1963 the University of Tulsa acquired from the private collection of John Bennett Shaw of Tulsa an outstanding collection of five modern authors. The acquisition includes virtually complete first edition collections of the works of William Faulkner, Ernest Hemingway, Thomas Wolfe, John Steinbeck, and Katherine Mansfield. Although the material has not yet been cataloged, there are over seven hundred books and journals along with many clippings, reviews, photographs, and ephemera. Several of the rare items are virtually unknown to bibliographers. Besides the first and subsequent editions of the primary sources that have appeared, the collection is especially rich in critical material, with special strength in Faulkner and Hemingway.

The strongest collection is the Faulkner section. The prize here is Faulkner's Marble Faun (1924). It is signed by Faulkner on the title page and has an inscription in the inside front cover also signed by him. Another rare Faulkner title is Turnabout (no date), which has been absent from many Faulkner bibliographies. This title was privately printed in Ottawa and is still in wrappers. The name written in this copy is Frank Case; this is the Frank Case of Algonquin fame. Another especially rare item in the Faulkner collection is Sherwood Anderson and Other Famous Creoles (1926). This book is a collection of illustrations drawn by William Spradling and arranged by William Faulkner. The copy in the university's holdings is number nineteen of 250 copies. This copy is
Mr. Staley is Assistant Professor of English at the University of Tulsa.

a special one, for most of the drawings are hand colored and signed by the subjects illustrated, such as Sherwood Anderson, "Ham" Basso, Lyle Saxon, and the thirty other subjects of the book. It is also signed by Estelle Faulkner Spradling "for Bill." The Faulkner collection also contains over twenty translations of the novels. Of special value to the university's graduate program is the large collection of critical books and articles on Faulkner. One scarce item among the criticism is a mimeographed speech by Robert Penn Warren entitled "William Faulkner and His South" with the formal invitation to the address delivered at the University of Virginia in 1951.

The Hemingway collection is not quite so extensive as this, but there are nearly two hundred items plus more than two hundred and seventy-five periodical clippings by and about Hemingway from newspapers, quarterlies, etc. The rarest single piece in the collection is a copy of the Oak Park High School Senior Tabula. In this 1917 edition appeared the "Class Prophecy" written by Ernest Hemingway. This is an extremely scarce Hemingway title, and it reveals his early gift for acute observation. Many of the foreign periodicals are also very rare.

The Steinbeck collection is naturally smaller than the Faulkner and Hemingway, because of the smaller body of work and less critical interest. This collection, 
however, is in especially good condition, and most of the editions are wrapped in their original dust jackets. The collection is virtually complete in its primary sources, and includes first editions of all the major and minor prose. The rarest title is perhaps the numbered edition of The Red Pony (1937). This copy is number 204 of 699 numbered copies signed by the author. Steinbeck's European popularity is reflected by the numerous foreign translations of his work. The collection includes over twenty-five first editions of translations in European and South American languages.

The Thomas Wolfe collection is, to my knowledge, complete so far as published first editions are concerned. This collection contains over one hundred and ten titles and one hundred and eighty clippings and radio scripts, reviews, reprints of monographs, and the like.

The last writer in the collection is the lone non-American, Katherine Mansfield. The New Zealand prose writer, best known for her short stories, had a long and versatile career up until her death in 1923. The Mansfield collection reflects her broad interests, both critical and creative. This collection contains over thirty-five primary sources and over fifty-five secondary sources. Many rare titles such as the Prelude (1918) are included.

\section{Anthropocentric Needs}

(Continued from page 290)

and eight liberal arts colleges located in the middle west. He categorizes these colleges as having (1) an academic orientation; (2) an "indecisive" or "bipartite" orientation; or (3) a practical orientation, in accordance with the proportion of bachelor's degrees awarded during a year in the "practical" fields of business and commerce, applied health and home economics, and education. If the proportion is 0.0 per cent to 33.3 per cent an academic orientation is awarded; 34.5 per cent to 48.8 per cent causes a college to be placed in the "bipartite" or "indecisive" category; and 49.7 per cent to 75.2 per cent places a school at the ex- tremity of the continuum in what is called the practical orientation. Examples of the three types are academic -Carleton; "indecisive"-Augustana in Illinois; and practical-Culver-Stockton. ${ }^{77}$

Another approach, developed by Robert H. Knapp and Linda A. Ehlinger for application to universities, assesses styles of scholarly production. Using data on the academic fields in which the fouryear graduates of various universities ultimately receive their doctorates, Knapp and Ehlinger developed a four-part typol-

"Land, "Practical and Academic Orientations of Liberal Arts Colleges," School and Society, LXXXXI, (March 9, 1963), 115. 
ogy of scholarly production: (1) the "Ivy League" style (in which the undergraduate divisions of universities are notably productive of students who eventually take doctorates in the humanities and social sciences, moderately productive in the physical and biological sciences, but unusually low in the field of education); (2) the "land grant" style (a very heavy contribution in the biological sciences, a moderate productivity in the field of education, and a notably low output of students who end up taking their Ph.D.'s in the humanities); (3) the "metropolitan-teacher" style (weak productivity in both the physical and biological sciences, substantial contribution in the humanities, and outstandingly productive in the field of education); and (4) the "technological" style (specially oriented to graduating students who go on in the physical sciences, but with contributions above the "land grant" style in the humanities).

Appropriate examples of the four styles are: (1) "Ivy League"-institutions of the Ivy League along with UCLA, the State University of Iowa, and the University of North Carolina; (2) "land grant"- the land grant universities of the middle and far west accompanied by Cornell and Brigham Young universities; (3) "metropolitanteacher"-metropolitan schools like New York University and the University of Pittsburgh, plus teacher institutions acquiring university status through evolution, like the State College of Iowa and North Texas State College; and (4) "technological"-MIT, California Institute of Technology, Carnegie Institute of Technology, etc. ${ }^{78}$ If the application of instruments which measure alienation indicate that youth culture dominates institutions in the "academic," "Ivy League," and "technological" categories and that apprentices tend to populate the "practical" and "metropolitan-teach-

\footnotetext{
78 Knapp and Ehlinger, "Styles of Scholarly Production," Journal of Educational Research, LVI, (January 1963), 243-48.
}

er" institutions, then librarians will have at hand the kind of systematic information needed to plot development and change.

The position taken in this paper should not be interpreted as that of the Luddites, those organized rioters who destroyed new machines in the English Midlands during the first part of the nineteenth century. Technological innovation is vital to the improvement of academic libraries. I argue only for the allocation of some of our resources to an understanding of human reactions to the physical and interpersonal settings provided for students in our libraries. It may be that we have emphasized technology over behavioral studies because of the relative ease with which it can be applied to library problems. Then, too, the social psychologist at work with paper and pencil cannot hope to produce the short run tangible outcomes that follow upon the engagement of a computer engineer. Behavioral studies assume a burdensome ongoing character because of the tenuousness of their predictions at any point in time.

In suggesting that the behavioral sciences should be utilized for the insight they can provide rather than for their predictive qualities, Harold Lasswell observed that "while the behavorial sciences conform to the logic of all science, the laws formulated at any given time may not continue to hold for future events."79 These qualifications, however, should not deter us from supporting behavioral studies. We must expect some imprecision and inconsistency when the object under study is man. The history of academic librarianship in its relation to knowledge is an account of humanistic emphasis. I see no reason why the library humanism of the mid-twentieth century should not be one of a systematic study of men as library users.

70 Lasswell, "The Normative Impact of the Behavioral Sciences," Ethics, LXVII, (April 1957-Part II), 38 . 